\title{
Transformaciones del Derecho del Trabajo y Orden Económico Globalizado
}

Fernando Valdés Dal-Ré Universidad Complutense de Madrid

Palabras clave: Fexibilidad laboral, descentralización productiva.

\section{RESUMEN:}

Como consecuencia de la recesión económica iniciada en los años 70 , la mayoría de los paises de la Unión Europea ban adoptado una serie de medidas normativas que se alejan de la función compensadora y protectora propia del Derecho del Trabajo.

Key words: flexible labour, productive decentralization.

\section{ABSTRACT:}

As a consequence of the economic recession begun in the seventies, most of the European Union countries have adopted several legal measures that are far away from the protector function characteristic of the Labour Law.

1. Una versión previa de este trabajo fue publicada en: -Descentralización productiva y desorganización del Derecho del Trabajo., Sistema, núms. 168/169, pp. 71-87. 
1. Derecho del Trabajo y Crisis Económica: del Trabajo Tf́pico a los Trabajos Att́picos

De conformidad con un juicio unánimemente compartido por la doctrina científica, los años finales de la década de los 70 marcan un cambio de rumbo en el ordenamiento laboral; al menos, en el eurocontinental. A resultas de la recesión económica habida en la primera mitad de esa década y de los efectos por ella inducidos en los niveles de empleo, la mayoría de los países de la hoy Unión Europea adoptan una serie de medidas normativas que, al margen de sus diferencias tópicas, empiezan a socavar algunos de los principios básicos sobre los que se había venido construyendo, no sin fatigas ni esfuerzos, lo que Hugo Sinzheimer había calificado, 50 años antes, como el aderecho emergente de nuestros tiempos": el Derecho del Trabajo². Por expresar la idea con un nivel superior de abstracción, tales medidas empiezan a cuestionar la doble e histórica función desempeñada, desde sus orígenes, por este sector del ordenamiento jurídico: de un lado, la función compensadora, consistente en establecer límites a la autonomía privada individual, moderando el juego de un mercado de posiciones contractuales asimétricas en beneficio del contratante débil, y, de otro, la función protectora, enderezada a rescatar del ámbito rudamente patrimonial el negocio jurídico a través del cual un tercero se apropia de los resultados del trabajo ajeno, erigiendo al trabajador en titular no sólo de posiciones contractuales de débito o crédito sino de derechos de contenido personal.

La ordenación jurídica del principio de estabilidad en el empleo ilustra de manera ejemplar las consecuencias de esta primera onda de mudanzas normativas; hasta el punto que se anuncia su "fin": el fin de la estabilidad de entrada, pero también del de salida ${ }^{3}$. La configuración legal del contrato de duración indefinida como la figura contractual socialmente típica de prestar trabajo por cuenta ajena y dependiente, y que había sido utilizada para concebir la relación laboral como una relación "estable y de larga duración, exclusiva y a jornada completa", entra en crisis, haciendo su aparición una constelación de contratos "atípicos" que tienden a difuminar el prototipo de trabajador utilizado como referente normativo; como patrón o estándar social para la reglamentación de la relación laboral obligatoria.

2. Cfr. Hugo Sinzheimer, "La esencia del Derecho del Trabajo", en Crisis económica y Derecho del Trabajo. Cinco estudios sobre la problemática humana y conceptual del Derecho del Trabajo, Madrid (Instituto de Estudios Laborales y de Seguridad Social) 1984, p. 77 (traducción española de la conferencia pronunciada en Düsserdorf (1926) en la Volkshochschule de Lipsia y publicada ese mismo año bajo el titulo "Das Wessen der Arbeitsrechts", en la obra de Hermes, G., Grundfragen des Arbeitsrechts, Leipzig (ADGP), 1926; la cita en p. 4).

3. Vid. Antonio Ojeda Avilés, .El fin de un principio (la estabilidad en el empleo)n, en AA.VV., Estudios de Derecho del Trabajo en memoria del Profesor Gaspar Bayón Chacón, Madrid (Tecnos) 1980 , pp. 467 y ss.

4. Cfr. Gino Giugni, "Il diritto del lavoro negli anni 80", Giornale di Diritto del Lavoro e di Relazioni Industriali 1982, núm. 15. pp. 374 y ss, luego recogido en Lavoro, leggi, contratti. Bolonia Ci Mulino) 1989, pp. 293 y ss (la cita en pág. 307). 
En su inicio, este conjunto de medidas, con una decidida voluntad de revisar a la baja el acervo jurídico reconocido en favor de los trabajadores o por ellos conquistado, fue presentado con un alcance coyuntural; su objetivo, reiteradamente confesado por los legisladores de aquél momento, quedaba circunscrito a combatir los efectos más perversos derivados del cambio del ciclo económico iniciado tras la conclusión de la II Guerra Mundial y que se había caracterizado por un crecimiento económico sostenido y una situación de pleno empleo. Una vez contenida la caída de la tasa de ocupación, el régimen jurídico anterior, de seguridad en el empleo, habría de ser restaurado. La utilización de técnicas legislativas propias de las situaciones de excepcionalidad (decretos leyes, leyes medidas o leyes a término) así parecía sugerirlo. Y así fue percibido también por la doctrina de la época, que acuñó y puso en circulación una afortunada noción que venía a sintetizar el sentido de las reformas normativas emprendidas: "el Derecho del Trabajo de la crisisns.

Pronto pudo constatarse, sin embargo, que las nuevas opciones de política de derecho carecían de esa declarada vocación de reversibilidad; que eran estructurales, pues estructural, se alegaba, estaba resultando la causa. "El tiempo de los intentos, de los prudentes experimentos, de los cautos sondeos" rápidamente se agotaría, siendo sustituido por una nueva "estación normativa" ${ }^{6}$ que, ya sin disimulo alguno, aspira a instaurar un orden normativo de nueva planta o, al menos, mestizo, en el que los elementos de novedad convivan con otros propios del ancien regime. El Derecho del Trabajo de la crisis dará paso así a un Derecho de Trabajo en la crisis, queriéndose significar con la alteración de la preposición la estabilidad alcanzada por la nueva situación económica y, por lo tanto, la normalidad jurídica de las medidas adoptadas para combatirla. Un sencillo cambio en los usos gramaticales facilitará la acomodación del lenguaje teórico a la nueva orientación política. La semiótica irrumpirá con fuerza en el ordenamiento laboral.

Durante los últimos años de la década de los setenta y, prácticamente, a lo largo de toda la década siguiente, el debate europeo por excelencia en el campo de las relaciones laborales estuvo centrado en "las nuevas formas de empleo"; unas formas de trabajo respecto de las cuales el contrato de trabajo estable y a jornada completa «deja de ser la estrella polar del Derecho del Trabajo" ${ }^{7}$. Entre la incredulidad y el criticismo, los laboralistas europeos próximos a las corrientes ideológicas prolabour concentraron buena parte de sus energías intelectuales en buscar respuestas a los cambios normativos; a unos cambios que, en opinión mayoritaria, habian hecho sältar por los aires el prototipo de trabajador que se había ido moldeando por el ordenamiento laboral a lo largo de casi un siglo de experiencia jurídica, arrastrando

5. Por todos, vid. Rafaelle di Luca Tamayo (a cura di), 11 diritto del lavoro della emergenza. Năpoles (Jovene) 1979

6. Los entrecomillados, en la -Introduzione. a la obra colectiva Il diritto del lavoro dopo l'emergenza, Milán (Giuffre) 1988 (cit. por Umberto Romagnoli, "Intervento, Lavoro e Diritto 1988, núm. 3, p. 404)

7. Cfr. Umberto Romagnoli, El Derecho, el trabajo y la historia, Madrid (CES) 1997, p. 170 
en su disolución una constelación de efectos desestructuradores sobre el propio ordenamiento laboral. Esta figura, la del trabajador, durante largas décadas declinàda en singular, hubo de pronto de conjugarse en plural $y$, en consecuencia, el lavero" se transformó en "lavori".

Reflexionando sobre la proliferación de estas nuevas formas de empleo, María Emilia Casas y yo mismo hacíamos notar, en 1989, que tales nuevas fórmulas de ocupación estaban produciendo el doble fenómeno de "la destipificación del contrato de trabajo y de sus rasgos predominantes y hegemónicos y de descomposición de los generales, inderogables y uniformes valores normativos de tutela del orden laboral", señalando cómo las tradicionales desviaciones del contrato-tipo, "que antes no. pasaban de ser figuras extravagantes en el orden político y común laboral industrial, se multiplicaban y diversificaban, adquiriendo una nueva pujanza. El pluralismo tipológico, afirmábamos, "no es ya más un episodio coyuntural, sino una nueva realidad estructural que se extiende imparablemente a costa del decrecimiento del trabajo estable y protegido, mermado también por el nuevo aliento tomado por el trabajo autónomo y cooperativon ${ }^{8}$.

\section{Flexibilidad Laboral y Transformaciones en la Organización de Empresa}

Apreciada con una cierta perspectiva histórica, confieso el desenfoque en que incurrimos los laboralistas de la época. Desenfocado fue, en efecto, el análisis efectuado: su diagnóstico y su metodología. Aquél debate, que poco más tarde tambiến habría de reproducirse en la mayoría de los países latinoamericanos ${ }^{9}$, versó sobre los efectos de las mudanzas normativas; o mejor aún, sobre algunos limitados efectos de este proceso de cambio. A partir de una constatación de hecho, cual fue la segmentación del mercado de trabajo propiciada, alimentada y organizada por ese nuevo e implacable Leviatán, el de la flexibilidad en la gestión de la mano de obra; que progresivamente terminará asumiendo un carácter impersonal y fatal, conforme a una visión organicista y darwiniana de la historia ${ }^{10}$, se dedujo el fin del prototipe social y, por tanto, normativo sobre el que se había edificado el orden jurídico laboral. Pero no se supo diagnosticar la verdadera causa de esos cambios; y, menoss aún, descubrir el escenario donde se estaban generando las transformaciones que ocasionaban las turbulencias sociales y normativas. Educados cómo habíamos sîdo en un método jurídico que había erigido al trabajador en la figura clave y esencial

8. Cfr. María Emilia Casas Baamonde/Fernando Valdés Dal-Ré, .Diversidad y precariedad de la contratación laboral en Españan, RL 1989, núms. 7/8, pp. 64,75 y 80. Vid, también ahi, los estudiós sobre nuevas formas de empleo en Inglaterra, Italia, Alemania y EE.UU.

9. Vid., para una visión de conjunto, Oscar Ermida Uriarte (Coord), La flexibilización del trabajo: un estudio internacional, Caracas (Diario de Tribunales) 1990 279

10. Cfr. Luc Boltanski/Eve Chiapello, Le nouvel esprit du capitalisme, Paris (Gallimard) 1999, 
del Derecho del Trabajo, no nos habíamos percatado de las formidables mutaciones que, de forma discreta pero constante, se estaban produciendo, desde mediados de los años 70, en la organización del trabajo.

No son estos momentos ni lugar oportunos para entrar en un minucioso análisis de los procesos de cambio apenas enunciados, bastando con indicar que éstos, aún compartiendo la común finalidad de incrementar la competitividad de las empresas en el nuevo orden económico, no han seguido idénticas trayectorias. Lo que me importa es levantar acta de estas formidables transformaciones. En fórmula tan resumida como acertada, Castells ha certificado la nueva realidad empresarial. "La experiencia histórica reciente - dirá el profesor de Sociología de la Universidad de Berckeley - ya proporciona algunas respuestas sobre las formas organizativas de la economía: todas se basan en redes, elementos fundamentales del que están y estarán hechas las nuevas organizaciones, capaces de formarse y expandirse por todas las calles principales y los callejones traseros de la economía global,"

En un tempus histórico muy breve, de apenas quince años, había tenido lugar una sustituçión del paradigma de la empresa o, por mejor decirlo, del paradigma organizativo de la empresa. El modelo de organización tradicional descansaba sobre tres pilares: el control del entero ciclo de producción de bienes y servicios (integración vertical), la autonomía de cada empresa en sus relaciones con otras y una gestión funcional jerárquica. Este modelo había sido sustituido por otro con rasgos estructurales de signo opuesto: fragmentación del ciclo productivo (integración horizontal), dependencia, coordinación y articulación en las relaciones interempresariales y una gestión que privilegia la autonomía funcional. La centralización organizativa cederá el paso a la descentralización y la autonomía, a la interconexión, interna y externa ${ }^{12}$.

Desde luego, estos cambios no se han traducido en un único tipo de organización. La formación de redes de subcontratación que giran en torno a grandes empresas difiere de la constitución de las redes horizontales que agregan pequeñas y medianas empresas en distritos industriales. Y la estructura de "telaraña" de las alianzas estratégicas entre las grandes empresas es distinta de la mudanza hacia la empresa horizontal ${ }^{13}$. Pero el elemento común a todas ellas es la red, forma organizativa socialmente típica en la economía globalizada. Por lo demás, también resulta ocioso recordar que la figura de la «empresa-red", en sus diversas y poliédricas variantes, convive con fórmulas organizativas propias del antiguo paradigma. En su conver-

11. Cfr. Manuel Castels, La era de la información. Economia, sociedad cultura, vol. 1, La sociedad red, $4^{2}$ Reimpresión, Madrid (Alianza Ed.) 1999, p. 160

12. Para una excelente descripción de estos procesos de cambio, vid., por todos, Castells, La era de la información, cit. pp. 179 y ss, de quien tomo las ideas contenidas en el texto.

13. Cfr., nuevamente, Castells; La era de la información (...), cit. p. 195 
en su disolución una constelación de efectos desestructuradores sobre el propió ordenamiento laboral. Esta figura, la del trabajador, durante largas décadas declinada en singular, hubo dé pronto de conjugarse en plural y, en consecuencia, el alavo:ro" se transformó en "lavori".

Reflexionando sobre la proliferación de estas nuevas formas de empleo, María Emilia Casas y yo mismo hacíamos notar, en 1989, que tales nuevas fórmulas de ocupación estaban produciendo el doble fenómeno de "la destipificación del contrato de trabajo y de sus rasgos predominantes y hegemónicos y de descomposición de los generales, inderogables y uniformes valores normativos de tutela del orden laboral", señalando cómo las tradicionales desviaciones del contrato-tipo, "que antes no pasaban de ser figuras extravagantes en el orden político y común laboral industriali, se multiplicaban y diversificaban, adquiriendo una nueva pujanza. El pluralismo tipológico, afirmábamos, "no es ya más un episodio coyuntural, sino una nueva realidad estructural que se extiende imparablemente a costa del decrecimiento del trabajo estable y protegido, mermado también por el nuevo aliento tomado por el trabajo autónomo y cooperativo" ${ }^{8}$.

\section{Flexibilidad laboral y Transformaciones en la Organización de Empresa}

Apreciada con una cierta perspectiva histórica, confieso el desenfoque en que incurrimos los laboralistas de la época. Desenfocado fue, en efecto, el análisis efectuado: su diagnóstico y su metodología. Aquél debate, que poco más tarde también habría de reproducirse en la mayoría de los países latinoamericanos ${ }^{9}$, versó sobre los efectos de las mudanzas normativas; o mejor aún, sobre algunos limitados efectos de este proceso de cambio. A partir de una constatación de hecho, cual fue la segmentación del mercado de trabajo propiciada, alimentada y organizada por ese nuevo e implacable Leviatán, el de la flexibilidad en la gestión de la mano de obrạ; que progresivamente terminará asumiendo un carácter impersonal y fatal, conforme a una visión organicista y darwiniana de la historia ${ }^{10}$, se dedujo el fin del prototipo social y, por tanto, normativo sobre el que se había edificado el orden jurídico laboral. Pero no se supo diagnosticar la verdadera causa de esos cambios; y, menos aún, descubrir el escenario donde se estaban generando las transformaciones que ocasionaban las turbulencias sociales y normativas. Educados cómo habíamos sido en un método jurídico que había erigido al trabajador en la figura clave y esencial

8. Cfr. Maria Emilia Casas Baamonde/Fernando Valdés Dal-Ré, "Diversidad y precariedad de la contratación laboral en España., RI. 1989, núms. 7/8, pp. 64,75 y 80. Vid, también ahí, los estudios sobre nuevas formas de empleo en Inglaterra, Italia, Alemania y EE.UU.

9. Vid., para una visión de conjunto, Oscar Ermida Uriarte (Coord.), La flèxibllizición del trabajö: un estudio internacional, Caracas (Diario de Tribunales) 1990 279

10. Cfr. Luc Boltanski/Eve Chiapello, Le nouvel esprit du capitalisme, Paris (Gallimard) $1999, p$. 
del Derecho del Trabajo, no nos habíamos percatado de las formidables mutaciones que, de forma discreta pero constante, se estaban produciendo, desde mediados de los años 70, en la organización del trabajo.

No son estos momentos ni lugar oportunos para entrar en un minucioso análisis de los procesos de cambio apenas enunciados, bastando con indicar que éstos, aún compartiendo la común finalidad de incrementar la competitividad de las empresas en el nuevo orden económico, no han seguido idénticas trayectorias. Lo que me importa es levantar acta de estas formidables transformaciones. En fórmula tan resumida como acertada, Castells ha certificado la nueva realidad empresarial. "La experiencia histórica reciente - dirá el profesor de Sociología de la Universidad de Berckeley - ya proporciona algunas respuestas sobre las formas organizativas de la economía: todas se basan en redes, elementos fundamentales del que están y estarán hechas las nuevas organizaciones, capaces de formarse y expandirse por todas las calles principales y los callejones traseros de la economía global" "'.

En un tempus histórico muy breve, de apenas quince años, había tenido lugar una sustitución del paradigma de la empresa o, por mejor decirlo, del paradigma organizativo de la empresa. El modelo de organización tradicional descansaba sobre tres pilares: el control del entero ciclo de producción de bienes y servicios (integración vertical), la autonomía de cada empresa en sus relaciones con otras y una gestión funcional jerárquica. Este modelo había sido sustituido por otro con rasgos estructurales de signo opuesto: fragmentación del ciclo productivo (integración horizontal), dependencia, coordinación y articulación en las relaciones interempresariales y una gestión que privilegia la autonomía funcional. La centralización organizativa cederá el paso a la descentralización y la autonomía, a la interconexión, interna y externa ${ }^{12}$.

Desde luego, estos cambios no se han traducido en un único tipo de organización. La formación de redes de subcontratación que giran en torno a grandes empresas difiere de la constitución de las redes horizontales que agregan pequeñas y medianas empresas en distritos industriales. Y la estructura de "telaraña" de las alianzas estratégicas entre las grandes empresas es distinta de la mudanza hacia la empresa horizontal ${ }^{13}$. Pero el elemento común a todas ellas es la red, forma organizativa socialmente típica en la economía globalizada. Por lo demás, también resulta ocioso recordar que la figura de la "empresa-red", en sus diversas y poliédricas variantes, convive con fórmulas organizativas propias del antiguo paradigma. En su conver-

11. Cfr. Manuel Castels, La era de la información. Economia, sociedad cultura, vol. 1, La sociedad red, 4² Reimpresión, Madrid (Alianza Ed.) 1999, p. 160

12. Para una excelente descripción de estos procesos de cambio, vid., por todos, Castells, La era de la información, cit. pp. 179 y ss, de quien tomo las ideas contenidas en el texto.

13. Cfr., nuevamente, Castells, La era de la información (...), cit. p. 195 
sión en modelos analíticos, los modelos teóricos rara vez pueden calificarse como puros; son, más bien, mestizos, consistiendo entonces la labor del observador social en detectar el modelo dominante. $Y$ este es, hoy ya, el de la empresa-red.

3. la Descentralización Productiva y la formación del Nuevo Paradigma de la EMPRESA-RED

Variado y plural ha sido, por otra parte, el utillaje utilizado en esta divisoria histórica. No creo alejarme de la realidad de los hechos, sin embargo, al afirmar que la herramienta que mejor simboliza este fenómeno ha sido la descentralización productiva, entendida como forma de organizar el proceso de elaboración de bienes y de prestación de servicios mediante el recurso a la contratación de proveedores y suministradores externos para la ejecución de ciertas fases o actividades ${ }^{14}$.

Configurada en estos términos, la descentralización productiva se caracteriza por dos rasgos, que constituyen sus notas de identidad: la fragmentación o segmentación del ciclo productivo y la externalización o exteriorización de ciertas fases, funciones o actividades de dicho ciclo. Desde una perspectiva macro, la descentralización productiva lleva asociadas, por tanto, dos consecuencias esenciales. La primera, de carácter económico, consiste en la introducción de un principio de división del trabajo entre las organizaciones empresariales ${ }^{15}$. El viejo principio de división del trabajo intraempresarial, estructurado en torno a la diversificación de las prestaciones de trabajo y a la estratificación jerárquica de los trabajadores en categorías monovalentes, da paso a una nueva versión en la que la especialización alcanza a la propia organización. La segunda consecuencia, ya de impronta jurídica, reside en el tipo de relaciones interempresariales que la descentralización productiva pide, sustentadas en vínculos de cooperación, de coordinación o de dependencia. Pero sobre este extremo, habrá ocasión de retornar más adelante.

Tal y como se la viene de definir, la descentralización productiva no es, desde luego, un fenómeno nuevo; ni lo es en el campo de la organización de empresas ni en el tráfico jurídico. Pese a ello, no me parece arriesgado afirmar que la descentralización productiva es la "partera. que ha ayudado a alumbrar ese nuevo paradigma de empresa en que

14. Con ligeras variantes, es esta la noción comunmente aceptada de descentralización productiva, a la que ya suele identificarse con el barbarismo outsourcing. Vid., por todos, Jesús Cruz Villalón, -Descentralización productiva y sistema de relaciones laborales", Revista de Trabajo y Seguridad Social 1994, núm. 13, pp. 7 y śs. Lourdes Martin Florez, outsourcing y teletrabajo: consideraciones juridico-laborales sobre nuevos sistemas de organización del trabajo. Revista Española de Derecho del Trabajo, 1995, núm. 71, p. 404 y Juan Rivero Lamas.La descentralización productiva y las nuevas formas de organización del trabajo, en AA.VV., Descenturalización productiva y nuevas formas de organización del trabajo, Madrid (MTAS) 2000, pp. 22 y ss

15. Vid. Francisco Blat Gimeno, .El marco socioeconómico de la descentralización productivan, en AA.VV., Descentralización productiva y protección del trabajo en contratas. Estudios en récuérilo de Francisco Blat Gimeno, Valencia (Tirant lo Blanch) 2000, pp. 27 y ss 
radica la empresa-red. Dos son, a mi juicio, las razones que explican la centralidad de la descentralización productiva en la transformación de la empresa; de su organización y de su funcionamiento: su expansión cuantitativa y su versatilidad funcional.

Por lo pronto, la descentralización productiva se ha generalizado y expandido, desplazándose de las zonas suburbiales de la economía en que habitaba y se movía al epicentro. La descentralización productiva es, en la actualidad de nuestros días, un fenómeno "multidireccional" ", masivamente utilizado en la producción de toda suerte de bienes y en la prestación de todo tipo de servicios, habiendo barrido las fronteras en las que se encontraba tradicionalmente recluida: la geográfica, pues se limitaba a países desarrollados, y la funcional, ya que operaba preferentemente en actividades económicas de ciclo productivo no constante (por ejemplo, construcción civil o naval).

La descentralización productiva es, hoy, una realidad planetaria, visible en economías de muy distinta estructura y desarrollo y utilizada en los más diversos sectores económicos. El principio de división del trabajo asociado a la externalización no sólo alcanza a las organizaciones empresariales; también tiene renovada traducción en el campo transnacional a través de las empresas maquiladoras, utilizadas actualmente como vehículos de la estrategia descentralizadora de los países desarrollados para reducir de forma drástica los costes laborales. Y la externalización es, además de un fenómeno ampliamente generalizado, una realidad multifuncional, que no afecta solamente a la producción de bienes o servicios; también actúa en su gestión y comercialización, penetrando, incluso, en funciones empresariales básicas o estratégicas, como pueden ser las de dirección.

La difusión y generalización experimentada, ha convertido la descentralización productiva en un fenómeno poliédrico, que se resiste a ser encorsetado en moldes o patrones uniformes, sean estos de carácter organizativo o sean de naturaleza jurídica. Bajo la simplicidad de su concepto, la descentralización productiva encierra "un variado conjunto de realidades heterogéneas $y$, con frecuencia, incluso contradictorias ${ }^{17}$. Centrando las consideraciones en la vertiente jurídica, la colaboración interempresarial, presupuesto base de la descentralización productiva, ha venido instrumentándose tradicionalmente en el tráfico jurídico a través de una figura contractual típica: el contrato de ejecución de obra o contrato de empresa.

En la actualidad, la estrategia descentralizadora ha diversificado y multiplicado los cauces de instrumentación mediante una doble vía. La primera ha consistido en utilizar categorías contractuales viejas, a las que ha enriquecido con nuevos pactos y estipulaciones. Los contratos de arrendamiento de servicios, de depósito, de transporte o de gestión de intereses ajenos (los contratos de comisión y de agencia) son, hoy, fórmulas contractuales de uso habitual para externalizar actividades empresariales. Incluso en ocasiones se recurre a contratos coaligados (arrendamiento de

16. Cfr. Rivero Lamas, -La decentralización productiva (...)., cit, p.21

17. Cfr. Blat Gimeno, "El marco socioeconómico (...)», cit. p. 20 
servicios y compraventa, si se pacta prestación de servicios y transmisión de activos) o a tipos contractuales complejos ${ }^{18}$.

La segunda vía de diversificación jurídica de la descentralización productiva está teniendo lugar mediante la creación de nuevos contratos. Los contratos de franquicia, de factoring, de merchandising, de facilities management, de logistica o de mantenimiento o suministro de informática conforman un pequeño elenco de este nuevo escenario contractual que encauza, en el ámbito civil o mercantil, las pulsiones de la descentralización productiva. La combinatoria de algunos de estos contratos da lugar a la figura de la empresa hueca" o "empresa sin trabajadores"; esto es, empresas especializadas en la intermediación entre la financiación, la producción y la comercialización, organizadas a partir de una marca o de una imagen comercial de prestigio.

Los vínculos jurídicos que nacen a resultas de los procesos de externalización tienen una naturaleza civil o mercantil. Sin embargo, la descentralización productiva no es un fenómeno ajeno al ordenamiento laboral, que tradicionalmente ha instituido unos mecanismos de protección en favor de los trabajadores que prestan trabajo en las empresas auxiliares; cuestión distinta es la de discernir si esos mecanismos son capaces de seguir ofreciendo su función protectora ante una estrategia descentralizadora tan compleja; variada y generalizada. Más adelante habrá ocasión de reflexionar sobre tan crucial aspecto, bastando por el momento indicar que la multiplicación de los instrumentos jurídicos puestos al servicio de la descentralización productiva es una conclusión que no sólo puede constatarse en el campo de las formas civiles o mercantiles de colaboración interempresarial; también se detecta en el ámbito de las relaciones laborales.

La figura que tradicionalmente ha definido el marco laboral de los procesos de externalización ha sido la contrata y subcontrata de obras y servicios de la propia actividad. Es esta, sin embargo, una institución sobrepasada y bordeada, cuya regulación no sólo obedece a una lógica anterior a la aparición del nuevo paradigma organizativo de empresa; también facilita, a través de la estremada porosidad de sus enunciados normativos, la huida de los procesos de externalización hacia fórmulaśs menos constrictivas, que eludan la aplicación del principio de co-responsabilidad entre empresa principal y empresas auxiliares. En tal sentido, la descentralización productiva ha sabido utilizar en su propio beneficio viejos senderos, hasta hace bien poco ajenos a fines de exteriorización, y ha entrado en otros nuevos, poniéndoles a su servicio. En el primer capítulo, puede citarse la disciplina de la transmisión de empresa, aplicable a una de las herramientas de descentralización productiva hoy más recurrentes, cual es la filialización de sociedades, y el trabajo autónomo. En el segundo, es de obligada mención el teletrabajo.

18. Vid. Salvador Del Rey Guanter/Carolina Gala Durán,"Trabajo autónomo y descentralización productiva: nuevas perspectivas de una relación en progresivo desarrollo y dependenciar, RL 2000, núms. $7 / 8$, p. 80 


\section{Descentralizacion Productiva y Desorganización del Derecho del Trabajo}

En una exposición al estilo de la presente, de carácter introductorio o propedéutico, no ha lugar a analizar, ni tan siquiera de manera superficial, las instituciones laborales a través de las cuales se canaliza la descentralización productiva. El propósito en esta segunda parte de mi exposición es ofrecer una panorámica de los efectos que las nuevas formas de organización de empresa en general y la descentralización productiva, en particular, están produciendo sobre las estructuras básicas del Derecho del Trabajo.

Reflexionando sobre estos temas, Spiro Simitis, uno de los más lúcidos juristas europeos de nuestros días, ha pronunciado esta sentencia: "la nueva organización del trabajo está produciendo una desorganización del Derecho del Trabajo" "'. Al hacer mías estas palabras, debo advertir que no me sumo a la difusa corriente de pensamiento que anuncia el fin del Derecho del Trabajo o. al menos, su destierro a un parque jurásico, visitado sólo por historiadores del derecho. Aquél, el Derecho del Trabajo, seguirá desempeñando, a largo plazo, la función de mediar en el conflicto social por excelencia en las formaciones sociales capitalistas.

Pero dando de lado estos gruesos problemas, más propios de la prospección político-social que del análisis jurídico, la afirmación de Simitis no me parece discutible. Las nuevas formas de organización de empresa han desorganizado el Derecho del Trabajo; aunque no sólo el ordenamiento laboral. Su impacto es apreciable en el ordenamiento jurídico en su conjunto, al que, de seguro y por otra parte, transciende. La empresa-red no es sino la manifestación organizativa de un nuevo orden económico-social o, por decirlo en los términos de Boltansky y Chiapello, "del nuevo espíritu del capitalismo", de un capitalismo "en plena expansión y profundamente regenerado ${ }^{20}$, que anuncia el fin de un ciclo y el comienzo de otro distinto que ya está cambiando la sociedad: sus valores culturales y sus pautas de comportamiento.

La desorganización que la descentralización productiva está ocasionando en el Derecho del Trabajo es apreciable en numerosos aspectos. Enseguida aludiré a los más significativos. Lo que me interesa hacer notar es que, por encima de sus consecuencias, la descentralización productiva está causando una deconstrucción de los tipos sociales manejados por el ya secular ordenamiento laboral como prototipos normativos de los sujetos de las relaciones jurídicas laborales.

La externalización de actividades deconstruye el paradigma normativo del empresario y, por derivación, de la organización de medios de la que es titular: la empresa.

19. Cfr. Spiro Simitis, .Il diritto del lavoro ha ancora un futuro?", Giornale di Diritto del Lavoro e di Relazioni Industriali 1997, núm. 79, p. 617

20. Cfr, Boltanski/Chiapello, Le nouvel esprit du capitalisme, cit. p. 18. quienes indican, con razón de esa expansión sin precedentes coincide con una degradación, también sin precedentes desde la gran crisis de 1929, de la situación económica y social de amplias capas de la sociedad. 
Pero también causa estragos en el paradigma normativo del trabajador, considerado no sólo en su condición de parte de una relación obligatoria sino, además y adicionalmente, como miembro de un grupo que agrega intereses comunes. La descentralización altera profundamente las reglas hasta ahora fijadas para el ejercicio de la acción colectiva. En mayor o menor medida, todas las consecuencias desorganizativas de la externalización sobre las estructuras básicas del Derecho del Trabajo pueden reconducirse a esta doble ruptura $o$, al menos, a esta doble destipificación de los paradigmas normativos; a la "quiebra de la validez de las nociones de trabajador y empresario con las que se han venido tejiendo las normas del Derecho del Trabajo hasta el presente "21.

No es mi intención, ni la ocasión me lo permitiría, entrar en un análisis detallado de todos y cada uno de los efectos desorganizativos que la exteriorización de actividades produce sobre el sistema de relaciones laborales. Pero para no razonar en el vacío, aludiré, bien que en términos esquemáticos, a los más significativos. En concreto, me detendré en examinar las consecuencias de la descentralización sobre los siguientes aspectos: la figura del empresario; el estatuto jurídico del trabajador; la acción colectiva y los contornos objetivos del propio Derecho del Trabajo. Innecesario resulta indicar, por lo demás, que la metodología analítica que se propone tiene fines meramente sistemáticos. Como cualquier otro sistema normativo, también el sistema laboral está formado por un universo de instituciones que actúan como engranajes de un conjunto dotado, al menos de manera tendencial, de unidad. Es esta perspectiva unitaria y en modo alguno la fragmentaria, deducida del juicio aislado sobre una o varias instituciones laborales, la que da sentido a la conclusión que a partir de ahora se pretende argumentar.

5. La Figura del Empresario: del Empresario Único a la Pluralidad de Poderes y ResponSABLIDADES EMPRESARIALES

La comparecencia de dos únicas partes en el proceso de formación del contrato de trabajo, cuyo concurso de voluntades da vida a una relación jurídica obligatoria, es un dato que pertenece a la fenomenología jurídica; es una máxima de experiencia que traduce la forma socialmente típica de prestar un trabajo por cuenta ajena y dependiente. Pero además de ello, la bilateralidad del contrato de trabajo, referida la noción tanto al número de partes como al de obligaciones que aquél negocio jurídico crea y a la estructura de las mismas, ha sido un constante compañero de viaje del Derecho del Trabajo; de su teoría y de su práctica normativa.

Esta nota, en efecto, ha sido utilizada por los ordenamientos para definir las posiciones jurídicas, activas y pasivas, de empresario y trabajador - sus prestaciones y contraprestaciones, sus derechos y deberes y sus facultades y responsabilidades -

21. Cfr. Rivero Lamas, «La descentralización productiva (...)», cit. p. 20 
y, en razón de ello, deducir las oportunas consecuencias jurídicas. Apreciadas desde la perspectiva del empresario, éstas pueden enunciarse de manera sencilla: quien hace suya la utilitas del trabajo por cuenta ajena y dependiente, ejerce de forma no compartida los poderes de dirección, tanto los poderes fuertes como los débiles, así como los poderes instrumentales anexos: el poder disciplinario y el poder de control. Este ejercicio no compartido, derivado de una titularidad contractual tampoco compartida, tiene una lógica contrapartida: el empresario es el único centro de imputación de responsabilidades. Por expresar la idea en términos sumarios: la condición de empresario es indivisible.

La simbiótica asociación existente entre contratante a título de empresario y ejercicio efectivo y real de los poderes derivados de dicho título no es sólo un principio de orden dogmático; es una regla de orden público normativo que los ordenamientos jurídicos se han cuidado tradicionalmente de preservar. La ruptura de esta regla $o$, lo que es igual, el desplazamiento o transferencia a sujeto distinto de quien concierta la relación laboral de las posiciones jurídicas de empresario ha quedado fuera del tráfico jurídico; hace ya tiempo que las legislaciones eurocontinentales calificaron esa ruptura como conjunto de maquinaciones o engaños jurídicos enderezados a defraudar los derechos de los trabajadores, introduciendo las oportunas reacciones con vistas a deshacer el mecanismo interpositorio y restaurar el efecto jurídico derivado de la bilateralidad del vínculo contractual.

Un valor menos absoluto ha tenido, sin embargo, la consideración del empresario como único centro de imputación de responsabilidades, principio éste que la práctica totalidad de los ordenamientos eurocontinentales procedió a derogar a partir de la década de los años 50 con vistas a reforzar los créditos laborales de titularidad de los trabajadores al servicios de las, hasta entonces, contenidas manifestaciones de descentralización productiva. La imputación de responsabilidades típicamente contractuales más allá de la esfera patrimonial de quien asume la condición de empresario no perseguiría, a la postre, sino localizar, a través de un encadenamiento de eventuales responsables, un último que sea solvente ${ }^{22}$.

El ordenamiento laboral español no se ha mantenido ajeno a estas tendencias; antes al contrario, se alineó con ellas, reprimiendo el prestamismo laboral y estableciendo medidas de tutela en favor de los trabajadores al servicio de las empresas auxiliares, señaladamente la responsabilidad solidaria, por las obligaciones salariales y de Seguridad Social, entre el empresario principal, de un lado, y el contratista y el subcontratista, de otro. No es cuestión ahøra de entrar a estudiar con detalle el régimen de la cesión ilícita de mano de obra y de las contratas y subcontratas. A los efectos que aquí se persiguen, de ofrecer una panorámi-

22. Cfr. Miguel Rodriguez-Piñero, -La regulación protectora del trabajo en contratas., Revista de Política Social 1972, núm. 93, pp. 7-8 
ca del impacto de la descentralización productiva sobre el estatuto jurídico del empresario, bastará con efectuar algunas observaciones generales.

La generalización y diversificación de los instrumentos jurídicos al servicio de la descentralización externa ha colocado en una situación de obsolescencia la norma de protección enunciada en el art. 42 del ET; por decirlo con mayor contundencia, la ha privado de eficacia jurídica y de efectividad social. Por lo pronto y en la medida en que el objeto del negocio jurídico al que se refiere aquél precepto, que es el arrendamiento de obra, se presenta como el resultado de un hacer, queda extramuros de la tutela dispensada por la técnica de la corresponsabilidad empresarial la mayoría de los nuevos contratos a través de los cuales circula actualmente la exteriorización de actividades: los que, aún cuando comportan una obligación de resultado, no tienen como objeto la ejecución de funciones específicas a realizar por encargo de una empresa principal e integradas en su ciclo (gestión de servicios ajenos o distribución); los que comportan un dar, en lugar de un hacer (suministro de bienes) o, en fin, los que, aun teniendo como obligación un hacer, ésta no es de resultado sino de actividad (facilities management o el mantenimiento de informática).

Pero el anquilosamiento del art. 42 no sólo trae causa en la pérdida del contrato de ejecución de obra de su naturaleza de instrumento socialmente típico de descentralización productiva; también proviene, y en mayor medida si cabe, de la inadecuación de la noción "propia actividad" como condición de aplicación del régimen jurídico previsto por aquél precepto. Como ha sido sistemáticamente señalado por un solvente sector de nuestra doctrina, es esa una noción que deja hoy fuera de tutela, precisamente, a los colectivos de trabajadores más vulnerables a la utilización de la descentralización con fines de degradación de las condiciones de trabajo; a aquellos trabajadores que prestan su actividad en ciertas empresas del sector servicios (limpieza, seguridad y vigilancia, por ejemplo) que se encuentran a menudo descapitalizadas, sin más utillaje que el que brinda su mano de obra no cualificada.

Son los fenómenos de descentralización interna, básicamente representados por el trabajo temporal prestado a través de las Empresas de Trabajo Temporal (ETT), lós que más han contribuido, en el doble terreno dogmático y normativo, a poner en crisis el estatuto clásico de la figura del empresario. La nueva forma jurídica de trabajar que la ETT instrumenta no sólo pone en paréntesis la radical unidad y unicidad de la relación obligatoria a la que da vida el contrato de trabajo; quiebra la propia noción del contrato de trabajo celebrado entre un trabajador y un empresario como fuente exclusiva de derechos y obligaciones. La ETT, que es a la que corresponde la condición formal de empresario, ni ejerce la integridad de los poderes derivados de esta titularidad ni soporta en régimen de monopolio las responsabilidades laborales; aquellos se distribuyen entre la ETT y la empresa usuaria por razón de la materia y estas otras bien se reparten entre las dos con idénticos criterios materiales bien dan lugar a fórmulas de co-responsabilidad. 
Pero al margen del acierto o inadecuación de las respuestas de nuestro ordenamiento laboral en relación a las formas de exteriorización de actividades, la descentralización productiva, al multiplicar los centros de imputación de cargas y responsabilidades y al diversificar los poderes de organización, ha desorganizado el patrón clásico de la figura del empresario. En el sistema tradicional de relaciones laborales, en el que el empresario controla el entero ciclo productivo y, en razón de ello, la fuerza de trabajo necesaria para producir el bien o prestar el servicio, no resulta difícil conocer ni la identidad ni la ubicación del titular de los derechos y deberes nacidos del contrato de trabajo; las más de las veces, éste, incluso, puede ser designado con un ligero movimiento de la mano. En el sistema actual, la figura del empresario tiende a difuminarse $o$, al menos, a perder la transparencia que el principio de seguridad jurídica pide; a disolverse en una red de telaraña cuyo efecto social más inmediato no está siendo otro que el de acrecer la posición de fuerza de las empresas ubicadas en el epicentro de la red sobre el mercado de trabajo globalizado.

\section{El Estatuto Jurfidico Del. Trabajador: de la Uniformidad a la Diferenclación Cualitattva}

La historia y la estructura del Derecho del Trabajo evidencian que es éste un sistema normativo que se ha ido madurando y desarrollando bajo un presupuesto: la uniformidad del estatuto jurídico de los trabajadores al servicio de un mismo empresario. Esta nota, en realidad, no ha hecho sino traducir la sustancial unidad del prototipo del trabajador, en buena medida incentivada y adquirida por la agregación de intereses comunes y por la cohesión social que procura la agrupación de trabajadores en un mismo espacio físico. La fábrica es el centro de producción de bienes. Y precisamente por eso, por cuanto el empresario adopta las decisiones sobre el qué y el cómo producir con vistas a optimizar su inversión, controlando el proceso de trabajo y coordinando las prestaciones laborales, la fábrica es el caldo de cultivo en el que afloran y se consolidan las prácticas de uniformidad de las condiciones de trabajo.

La descentralización productiva ha hecho saltar por los aires aquél presupuesto. La uniformidad ha dado paso a la diversidad. Pero ésta no sólo ha de entenderse en clave de pluralidad; de una pluralidad alimentada por los variados incentivos (normativos, jurisprudenciales y de gestión de la mano de obra) destinados a recuperar para el contrato de trabajo los espacios de autonomía históricamente perdidos o, si se quiere expresar la idea en otras palabras, dirigidos a poner a disposición del empresario (o, mejor, del management) mayores márgenes de elasticidad y libertad en la organización del trabajo. La diversidad equivale, ante todo, a sinónimo de diferenciación y segmentación; de un tratamiento que estratifica a los trabajadores de la empresa-red en función de la calidad de su empleo. Esta, la calidad de las condiciones de trabajo, ya no se mide o no sólo se mide en razón de los criterios más tradicionales, como pueden ser, por ejemplo, las 
habilidades profesionales y la experiencia del trabajador o los resultados económicos de la empresa. Los patrones o estándares de referencia que definen el estatuto jurídico del trabajador pueden ser otros, tales como el valor añadidó del trabajo al producto final y, sobre todo, la posición delpropio trabajador en la empresa-red: a mayor lejanía del epicentro, las condiciones de trabajo tienden a degradarse.

De todos los efectos de las nuevas formas de organización de la empresa, es éste, muy probablemente, el de consecuencias más perniciosas, formulado éste juicio desde una perspectiva tanto macrosocial como microsocial. La afirmación requiere un razonamiento algo más sumario que el de su simple enunciado.

Las investigaciones económicas y sociales ya disponibles evidencian que, en el curso de las dos últimas décadas, ha tenido lugar un alarmante proceso al que Robert Castel ha calificado, no de "exclusión socialn, sino de "invalidación social". Me refiero a la aparición de grupos y colectivos sociales que ni siquiera se prestan a la "explotación"; se colocan en situación de "supernumerarios sociales" ante la convicción de que no poseen competencias que puedan transformarse "en valores sociales "23. El empobrecimiento de la población en edad activa, el crecimiento de los niveles de desempleo, el ascenso de las tasas de siniestralidad laboral y la explosión de las tasas de precariedad laboral, entreveradas con un uso recurrente de fórmulas de trabajo a tiempo parcial que multiplican la situación de precariedad, ofrecen algunas claves explicativas de estos fenómenos.

Por otra parte, y manteniendo aún el razonamiento en ese mismo plano macro, suele ser habitual entre los observadores sociales afirmar que el desarrollo y consolidación de las nuevas formas de organización del trabajo trae causa directa en el desarrollo de las tecnologías. La extensión de los fenómenos de exteriorización - ha sido argumentado entre nosotros por uno de los mejores especialistas en la materia - es el resultado de la universalización de las nuevas tecnologías de la informática y de la comunicación ${ }^{24}$.

Qué la aplicación de las tecnologías al mundo empresarial ha desempeñado, desempeña y seguirá desempeñando un muy destacado protagonismo en las estrategias descentralizadoras, es una afirmación sobre la que no vale la pena discutir. Pero este renovado tecnocentrismo, que vincula la expansión de la descentralización y la ruptura del paradigma clásico de empresa a los avances tecnológicos, ofrece una visión reduccionista de una realidad bastante más compleja. Como ha razonado Manuel Castells, las transformaciones organizativas no son consecuencia mecánica de los cambios tecnológicos. Aquellas se produjeron independientemente de éstos, como respuesta "a la necesidad de afrontar un entorno operativo en evolución constante ${ }^{25}$.

23. Cfr. Robert Castel, Les metamorphoses de la question sociale. Une chronique du salartal; Paris (Gallimard) 1999, pp. 28-29

24. Cfr. Cruz Villalón, -Oursourcing y relaciones laborales", cit, p. 257

25. Cfr. Castells, La era de la información (...), cit. p. 197. 
El modelo de lo que ha venido a denominarse empresa "escueta" (o uescueta y mezquina") se basa en ahorros de mano de obra mediante el recurso, entre otros elementos, al empleo masivo de trabajo subcontratado ${ }^{26}$, el cual se presta, a su vez, en régimen de precariedad laboral (temporalidad o trabajo a tiempo parcial: o ambos simultáneamente) y de precariedad salarial. Dicho en otras palabras, los fenómenos de externalización están en la base de la expansión y difusión de las distintas modalidades de contratación temporal y de trabajo a tiempo parcial. Cierto es que la reducción de costes laborales no es el único factor de la descentralización; pero sí es una ventaja perseguida por las estrategias descentralizadoras y que, de seguro, ha anidado en algunas de las opciones de política de derecho adoptadas por los poderes públicos en los últimos años así como influido en algunas interpretaciones jurisprudenciales de esta misma época ${ }^{27}$.

Es en este entorno en el que se explica que la descentralización productiva haya resultado, en ocasiones, sinónima de degradación y deterioro de las condiciones del empleo, enjuiciadas no sólo en términos salariales sino, más en general, en términos de calidad del trabajo y de protección social. El masivo recurso de las empresas colaboradoras y auxiliares de la principal a las modalidades de contratación temporal, consagrado como práctica lícita por una discutible jurisprudencia que vincula la temporalidad de los contratos de trabajo al negocio mercantil; el establecimiento de bajas condiciones de trabajo para los trabajadores de sectores enteros que funcionan en régimen de descentralización (por ejemplo, seguridad o limpieza), en ocasiones procedentes de la empresa principal y que quedan extramuros de la normativa sucesoria ${ }^{28} \mathrm{o}$, en fin, la introducción por vía de convenio colectivo de condiciones de trabajo distintas y menos favorables para los trabajadores que se incorporan a empresas con posterioridad a los procesos de filialización adoptados constituyen hoy prácticas habituales de las estrategias decentralizadoras de nuestro sistema de relaciones laborales. Y dan cuenta del inquietante efecto de dualización del mercado de trabajo alentado por la descentralización productiva.

26. Cfr. Castells, La era de la información (...), cit. p. 192

27. Para un análisis de conjunto de la jurisprudencia en estas materias, vid Abdón Pedrajas Moreno,"Relaciones de carácter interempresarial: subcontratación,cesión, sucesión, grupos de empresa», en Juan Manuel Ramírez Martínez/Tomás Sala Franco, Unificación de doctrina del Tribunal Supremo en materia laboral y procesal laboral (Estudios en homenaje al Profesor Efrén Borrajo Dacruz), Valencia (Tirant lo Blanch) 1998, pp. 227 y ss.

28. En torno a esta polémica, vid. Fernando Valdés Dal-Ré, La transmisión de empresa y las relaciones laborales, Madrid (MTAS) 2001, pp. 55 y ss y la jurisprudencia, nacional y comunitaria, ahí recogida. 


\section{La Acción Colectiva}

La expansión de las técnicas de externalización ha ocasionado importantes transformaciones en el tejido productivo. Por lo pronto, los procesos de descentralización, al multiplicar la cadena de empresas auxiliares y externalizar funciones no estratégicas hasta entonces desempeñadas por las empresas, estimulan la creación de empresas de pequeñas dimensiones, cuyo índice de falencia es, por otra parte, muy elevado. En las últimas dos décadas, la pérdida de empleos en el sector industrial de los países de la Unión Europea se ha concentrado, sobre todo, en las grandes empresas; las pequeñas y medianas empresas, por el contrario, han experimentado una tasa de decrecimiento más moderada, habiendo contribuido, en mayor medida, a la creación de empleos en el sector servicios.

Constatado el florecimiento de la pequeña empresa, compuesta en numerosas ocasiones por el empresario-trabajador y un número reducido de asalariados, conviene aclarar que la descentralización productiva no ha puesto en crisis la figura de la gran empresa. La que está en crisis es la gran empresa como organización de integración vertical y jerárquica. La otra gran empresa, la que se erige en centro de concentración de capital, diversificando y dislocando geográficamente sus actividades, ha salido robustecida en el nuevo orden económico globalizado.

La descentralización productiva, en segundo lugar, también ha solido ir acompañada de un redimensionamiento de la empresa; impacto éste más visible, en esta ocasión, en la mediana y gran empresa. La reducción de efectivos en las más importantes compañías españolas mediante fórmulas de baja incentivada y, sobre todo, de prejubilaciones por razón de edad ${ }^{29}$ ha constituido una constante de nuestro sistema de relaciones laborales durante la última década. Como regla general, los redimensionamientos en las grandes empresas no han comportado, sin embargo, una pérdida neta de empleos en el sector equivalente al volumen de trabajadores despedidos por razones técnicas o económicas, habiéndose producido un fenómeno de sustitución a través de una doble vía: la subcontratación y la conversión de los antiguos asalariados en autónomos.

La acción combinada de estos dos factores (crecimiento de las pequeñas empresas y redimensionamiento de las grandes) es la causa de los efectos desorganizadores de la externalización sobre la acción colectiva. De manera gráfica, la idea ha sido resumida por Umberto Romagnoli: "a caballo de los años 60 y 70, el derecho del trabajo italiano entró en la fábrica para hacerla más democrática (...), pero las fábricas se han vaciado. De improviso y bastante deprisan ${ }^{30}$.

29. Bâsicamente, en los sectores del automóvil, telefonía y energético. Vid., los datos, para el período 1994-1998, y una contundente crítica a estas prácticas, en Pedro Gete Castrillo, La edad del trabajador como factor extintivo del contrato de trabajo, Valencia (Tirant lo Blanch), 2001, pp. 45 y ss.

30. Cfr. Umberto Romagnoli, -Globalización y Derecho del Trabajo, Revista de Derecho Social 1999, núm. 5, p. 10 
Pero las fábricas no sólo se han vaciado de trabajadores; también se han dislocado territorialmente y desmembrado organizativamente. La figura de la gran empresa con decenas de miles de trabajadores, socialmente cohesionados por el ejercicio de la acción sindical y prestos a movilizarse en defensa de unos intereses comunes, empieza a formar parte de la prehistoria de la economía globalizada. Es éste, en efecto, un tipo de empresa en buena parte ya sustituido por una nueva generación de organizaciones empresariales cuya estructura rememora la red de telaraña. En el epicentro se encuentra la empresa holding o matriz, casi "hueca" en efectivos humanos; en el primer círculo concéntrico, se hallan las empresas nacidas de procesos de filialización y que, al diversificarse por líneas de negocio o actividad, reducen drásticamente el número de trabajadores; y éstas, a su vez, actúan como empresas principales de un universo de empresas auxiliares en las que los empleos se prestan bajo títulos muy diversos: dependiente, cooperativo y autónomo.

Este entorno organizativo modifica los tradicionales presupuestos de hecho de los sistemas pluralistas de relaciones laborales. Los procesos de vaciamiento y dislocación de las empresas, por lo pronto, dificultan la implantación de los sujetos que agregan los intereses colectivos de los trabajadores. $Y$ en segundo lugar, abren nuevos escenarios en la acción colectiva, de fronteras funcionales más difusas (Grupo de Empresa, sectores descentralizados o empresas auxiliares) y a menudo privadas de la tradicional nota de cohesión social. La cohesión social. fundamento de la acción colectiva, tiende a erosionarse.

\section{El Ámbito Objetivo del Derecho del Trabajo: el lugar del Trabajo Autónomo}

En cuanto forma jurídica de trabajar, el trabajo autónomo no sólo no constituye ninguna novedad. Esta figura ha venido siendo utilizada tradicionalmente por el Derecho del Trabajo para delimitar en negativo su objeto; ha operado como factor de identificación del ámbito de aplicación del propio ordenamiento laboral. El trabajo por cuenta ajena y dependiente no es una simple abstracción jurídica; es el lento resultado de un proceso de tipificación jurídica de una forma de trabajar noautónoma.

No es cuestión ahora, desde luego, de entrar a discutir los elementos constitutivos del trabajo autónomo, que nos conducirían, por derivación, a reflexionar sobre los elementos constitutivos del trabajo por cuenta ajena y dependiente. Lo que aquí importa apuntar es la formidable expansión que el trabajo autónomo ha experimentado en el curso de los últimos años de la mano de la descentralización productiva; expansión ésta alentada e incentivada, por otra parte, mediante acciones normativas, nacionales y europeas. La externalización de actividades no solamente ha expandido el trabajo autónomo; también ha cambiado el perfil del traba- 
jador autónomo en un doble sentido. La industria artesana, el pequeño comercio, el transporte de reducidas dimensiones, los oficios tradicionales y las denominadas profesiones liberales han constituido los nichos de empleo tradicionales del trabajo autónomo, ejercido, de otro lado y las más de las veces, a lo largo de toda la vida laboral. No es éste o no es sólo éste ya, sin embargo, el perfil profesional del trabajador autónomo, en cuya actividad laboral, por otra parte, se intercalan y suceden períodos de prestación de trabajo por cuenta ajena.

El principal problema que suscita este florecimiento del trabajo autónomo es el de discernir su ubicación en el ordenamiento jurídico y, más en concreto, precisar la función reguladora, si alguna, que corresponde al ordenamiento laboral; problema éste que, como es bien sabido, ha abierto un debate en el que lo que está a discusión es la configuración del propio Derecho del Trabajo como sistema normativo del trabajo por cuenta ajena y dependiente. Desde la disolución del contrato de trabajo en una nueva figura contractual, el contrato de actividad, hasta la transformación del Derecho del Trabajo en un ordenamiento de la actividad profesional, las propuestas e iniciativas hasta ahora sugeridas son tan variadas como heterogéneas ${ }^{31}$.

Sin intención de terciar en un debate de tan grueso calado, que afecta a las estructuras más esenciales del Derecho del Trabajo, no comparto la idea de quienes postulan la extensión al trabajador autónomo, sin matices ni reservas, de la tutela que el ordenamiento laboral dispensa al trabajador subordinado. Y, menos aún, de quienes, desde una posición aparentemente opuesta, sostienen la conveniencia de desmantelar las instituciones típicas de este sector del ordenamiento jurídico y su sustitución por otras nuevas que permitan la reconstrucción de un tipo contractual que acoja ambas formas de trabajar con vistas a facilitar la parificación de su tratamiento normativo.

Pero al margen de estas propuestas extremas, huérfanas hasta el presente de traducción normativa, la utilización del trabajo autónomo como instrumento privilegiado de la externalización de actividades ha tenido el efecto de desvelar las carencias de la protección jurídica del trabajo autónomo y, por consiguiente, la exigencia de instituir un estatuto profesional al que no pueden ser ajenos algunos mecanismos de tutela ya probados en el ordenamiento laboral. Aún con todas sus imperfecciones y su complejidad jurídica, las regulaciones alemana de los usemi trabajadores" e italiana de los "parasubordinados" ofrecen elementos para la reflexión.

31. La bibliografía empieza a ser ya abrumadora. Vid., por todos, Supiot, Au-delà de lemploi, Paris (Flammarion), pp. 27 y ss 